International Use of Tranquilizers

The annual number of prescriptions for tranquilizers and sedatives increased by $60 \%$ in England and Wales between 1965 and 1970 until in that year 17.2 million prescriptions for these drugs were dispensed under the N.H.S. (this figure does not take into account drugs prescribed in psychiatric institutions). There is evidence to suggest that the annual number of prescriptions is still increasing, while the practising doctor now has no fewer than 70 drugs (representing some 29 chemical substances) from which to choose when prescribing a drug of the sedative-tranquilizer type. ${ }^{1}$

In view of these statistics, the results of a recent survey carried out in nine western European countries are of interest. ${ }^{2}$ An attempt was made to assess the prevalence of use of tranquilizer and sedative drugs, and the national attitudes towards their use, by interviewing randomly selected samples of people aged 15 years or more in each country. The numbers of respondents included in the analysis varied from 1,000 in Denmark to 2,377 in France.

The proportion of people in the original sample who were successfully interviewed ranged from $67 \%$ in the United Kingdom to $93 \%$ in the Netherlands, with a mean response rate of $85 \%$. There were three main questions. Firstly, had the respondent used a tranquilizer or sedative drug on one or more days during the past 12 months? Secondly, if the answer to this question was yes, had any such drug been used by the respondent daily for one month or more during the last year? Finally, did the respondent consider the drugs to do more harm than good to people using them? Great care was taken to standardize the questionnaire and interviewing procedure in the different countries.

The proportion of all people using tranquilizer or sedative drugs on one or more occasion in the last year ranged from $17 \%$ in Belgium and France to $10 \%$ in Spain (14\% in the United Kingdom). Not unexpectedly, in most countries the proportion of women who had used the drugs was about twice that of men, and the rate of use increased with age.

Using the more stringent criterion of daily drug use for one one month or more during the year, the percentage of users ranged from 3\% in Italy to $9 \%$ in the United Kingdom with a mean of $6.5 \%$. If these statistics for heavy use are correct, it may come as a surprise that only around twice as many people reported ever using the drugs at all. It seems quite possible, however, that respondents may have failed to recall occasional use of "pills or medicines prescribed to help to calm people down or make them feel less nervous or upset" whereas regular use is less likely to have been overlooked.

National attitudes towards tranquilizers and sedatives appeared to bear little relationship towards drug use in the particular country. In five of the countries around $50 \%$ of persons interviewed believed that tranquilizers or sedatives do more harm than good to people taking them; while between 15 and $33 \%$ of users held this opinion.

This attitude, together with the enormous annual cost to the Health Service of these drugs, must raise once again the question of the appropriateness of their prescription. In a survey of all psychotropic drugs used in general practice Parish $^{3}$ found that fewer than $50 \%$ of patients treated with such drugs had been diagnosed as suffering from psychotic or neurotic disorders or physical disorders presumed to be of psychogenic origin. Eighteen per cent. were labelled as suffering from a physical disorder (hypertension, ischaemic heart disease, musculoskeletal disorders) for which the main form of treatment being used was psychotropic drug therapy, and most of the remainder had only isolated mental or physical symptoms.

Finally, with an appreciable proportion of the population consuming tranquilizers and sedatives their safety needs to be under constant review. So far no major side effects have been ascribed to diazepam and chlordiazepoxide, the two drugs accounting for a large share of the total number of prescriptions. The manufacturers warn only of drowsiness associated with high dosage, the occurrence of mild ataxia after excessive dosage, and the care which needs to be exercised when the drugs are used with alcohol or in patients with organic cerebral changes. While this is reassuring, it is important that any previously unsuspected or major adverse reactions should be reported to the Committee on Safety of Medicines so that surveillance may continue.

1 Monthly Index of Medical Specialities (MIMS). London, Haymarket Publishing Ltd., 1974.

2 Balter, M. B., Levine, J., and Manheimer, D. I., New England Fournal of Medicine, 1974, 290, 769 .

${ }^{3}$ Parish, P. A., Fournal of the Royal College of General Practitioners, 1971, 21, Supplement 4

\section{A Decade of Service}

The tribulations of general practice were reaching their worst when Dr. J. C. Cameron was elected Chairman of the General Medical Services Committee on 28 March 1964. ${ }^{1}$ He steps down from this hot seat ${ }^{2}$ at a time when the hospital service is in serious disarray. Though general practice is unlikely to escape unscathed from the present N.H.S. crisis it has developed a confidence and stability that could well prove invaluable in helping to rebuild morale in hospitals. Doctors, and, indeed, all those who hope for a flourishing Health Service, have much to thank Dr. Cameron for in this renaissance of general practice. Too many doctors tend to be cynical about medicopolitics while too few take the trouble to contribute. What they probably fail to appreciate is that nowadays negotiating for the profession is virtually a full-time activity. Despite this heavy commitment Dr. Cameron-along with his negotiating colleagues-has continued with his practice, thus retaining an all important link with day-to-day clinical medicine. Losing contact with the electorate is an occupational hazard for any politician-and medicopoliticians are no exception. Dr. Cameron's success has been founded on a shrewd appreciation of what doctors in their surgeries feel about their work-including how far doctors are willing to explore new pathways. Perhaps one of his most important contributions was his support of vocational training for general practice-which only a few years ago was a contentious dream, but is today an accepted reality. $\mathrm{He}$ has earned the respect and affection of family doctors. Fortunately, his experience will not be lost to the B.M.A. and members of both the G.M.S. Committee and the Council will welcome Dr. Cameron's continued presence on the back benches.

\footnotetext{
1 British Medical fournal Supplement, 1964, 1, 111

${ }^{2}$ British Medical fournal Supplement, 1974, 2, 141.
} 